\title{
A Comparison Of Video Formats For Online Teaching
}

Ross A. Malaga, Montclair State University, USA

Nicole B. Koppel, Montclair State University, USA

\begin{abstract}
The use of video to deliver content to students online has become increasingly popular. However, educators are often plagued with the question of which format to use to deliver asynchronous video material. Whether it is a College or University committing to a common video format or an individual instructor selecting the method that works best for his or her course, this research presents a comparison of various video formats that can be applied to online education and provides guidance in which one to select.
\end{abstract}

Keywords: Online Teaching; Video Formats; Technology Acceptance Model

\section{INTRODUCTION}

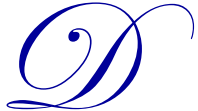

istance learning is one of the most talked-about topics in higher education today. Online and hybrid (or blended) learning removes location and time-bound constraints of the traditional college classroom to a learning environment that can occur anytime or anywhere in a global environment.

According to research by the Online Learning Consortium, over 5 million students took an online course in the Fall 2014 semester. This represents an increase in online enrollment of over $3.9 \%$ in just one year. In $2014,28 \%$ of higher education students took one or more courses online (Allen, I. E. and Seaman, J, 2016). With this incredible growth, albeit slower than the growth in previous years, institutions of higher education are continuing to increase their online course and program offerings. As such, institutions need to find easy to develop, easy to use, reliable, and reasonably priced technologies to deliver online content.

While distance learning can occur in a variety of ways, asynchronous learning is the fastest-growing approach. Typically in an asynchronous learning environment, students can view course material such as lectures or short videos online whenever and wherever they choose with Internet access.

With the rise of YouTube, Vimeo, and other hosting sites, online videos have become one of the most common functions of Internet users. According to a global online survey by Accenture, a leader in global management consulting, more than ninety percent of consumers of all ages in major geographies around the world (United States, United Kingdom, France, Brazil, Italy and Spain) are now watching video content over the Internet. Of those, only 45 percent are satisfied or very satisfied with the consistency in user experience when accessing video services across devices. They identified that video quality and stream download time were among the most important technical features they look for in an Internet video service (Vernocchi, 2013).

Video has proven to be a highly effective educational format. For example, Armstrong, et. al. (2011) compared the use of video with written material in understanding the importance of sunscreen use. They conclude that the video group retained more knowledge and rated their educational format (video) as more useful and appealing than the written format.

Clearly, watching videos on the Internet is commonplace today. As such, various video formats are available in the marketplace for viewing video material online. However, educators are often plagued with the question of which format to use to deliver asynchronous video material. Whether it is a College or University committing to a common video format or an individual instructor selecting the method that works best for his or her course, this research will present a comparison of various video formats that can be applied to online education. 


\section{IMPORTANCE}

Choosing a video format for online or hybrid courses may be the last factor an instructor considers during the course development process. In some cases, the video format might be dictated by information technology departments or available software. However, the video format chosen may play a significant role in the success or failure of the course.

The widely used technology acceptance model (TAM) states that technologies with a high perceived usefulness and a high perceived ease of use are more likely to be used (Davis, 1989). In a hybrid or online format, the perceived usefulness of an instructional video is derived from the content of that video. As the video format is separate from the content, this paper will focus primarily on ease of use.

Perceived ease of use needs to be addressed both from the faculty and student perspectives. In this case, ease of use for the faculty incorporates both cognitive load (how easy is it to learn) and time required to perform the task. From the student perspective, the video needs to be able to play correctly on multiple platforms (operating systems, mobile devices, etc.), have good quality, and play (or download) quickly (Chester, 2011; Hill and Nelson, 2011). Kay (2012) concluded that these types of technical issues were a major factor in the non-use of online video by students.

Today the faculty member contemplating the use of video can choose from various formats. Some of the most widely used are Windows Media Video, Flash, QuickTime, Audio Video Interleave, and MPEG-4 (and the associated. $\mathrm{m} 4 \mathrm{v}$ format for iTunes). All of these formats may be rendered in numerous dimensions, to accommodate everything from small portable devices to large screen televisions.

In addition, all of these formats allow the video author to choose among various encoding schemes and other technical options. For example, most video formats allow the author to manipulate the video encoding rate (which can affect the quality of the video and the size of the file) and the audio format. Also, many video formats support multiple codecs (the actual algorithms used to encode files in that format).

The combination of formats, sizes, and technical options can result in thousands of possible permutations. This could be overwhelming for faculty who need to choose among the various options.

\section{VIDEO FORMAT OVERVIEW}

In this section, we provide an overview of the most widely used video formats.

\section{Audio Video Interleave (.avi)}

Microsoft first introduced Audio Video Interleave (which produces avi files) in 1992. By default avi files are produced with no compression. Typically, this results in large files sizes. Because they are uncompressed, and most video editing software can easily import them .avi files are often used when recording, before converting to other formats for Web-based distribution.

Various codecs (e.g., DivX) allow faculty to produce .avi files with a high level of compression. However, doing so would require both the faculty member and students to install the codec.

\section{Windows Media Video (.wmv)}

Windows Media Video (.wmv) is a video compression method first proposed by Microsoft in 2003 (WMV9) and accepted as an open standard in 2006 (as VC-1). The .wmv standard allows for compression via a large array of codecs. These codecs allow for both lossless and lossy compression in a wide number of resolutions and bitrates. The number of options available for .wmv increases the complexity for faculty trying to choose the best format.

It should be noted that the .wmv format allows for digital rights management (DRM). Therefore, .wmv might be useful for the faculty member who wishes to tightly control the use of his/her video material. 
Windows Media Player (which comes installed with the Windows operating system) is capable of playing .wmv files. So students who use PCs should have no problem playing these files. However, students who want to view the video on a non-PC device (Mac, tablet, mobile phone, etc.) would need to install software. Appropriate software may not be available for all devices.

\section{Flash (.flv or .swf)}

Flash is a video format used to stream video over the Internet for viewing using Adobe's Flash Player. Most of the major online video sites, such as YouTube, Hulu, and Vimeo, as well as a huge number of Websites that contain video, support the Flash format. The main drawbacks to Flash are that it requires students to install a browser plugin, and it is not compatible with iOS based devices (iPod, iPhone, iPad).

\section{QuickTime (.mov)}

QuickTime is a proprietary video compression format developed by Apple. To view .mov files on either Windows PCs or Macintosh computers, the QuickTime player is required. While this may require students to download software, QuickTime is installed along with iTunes (which many students are likely to have previously installed). The International Organization for Standardization (ISO) used QuickTime as the basis for the MPEG-4 standard (see ISO/IEC 14496-14:2003). Therefore, use of .mov has been largely replaced by MPEG-4.

\section{MPEG-4 (.mp4)}

As mentioned above MPEG-4 (.mp4) is an international video format standard based on the QuickTime File Format (QTFF). The MPEG-4 standard allows for the use of various codecs and compression schemes. However, MPEG-4 Part 10 (also known as Advanced Video Coding or AVC) using the H.264 compression codec has become a de facto standard. It is the standard used for high definition Blu-Ray discs and on popular video streaming sites, such as YouTube and iTunes.

\section{HEAD TO HEAD COMPARISON}

Each of the video formats discussed above were compared to determine ease of use. We operationalize ease of use by:

1. Determining the file size for a sample video in each format (file size is used as a proxy for download time as the actual time will vary depending on Internet connection speed),

2. Determine the portability of each format (on which systems it will play without a plugin or software download), and

3. Determine how easy it is to distribute the video (whether the file can be downloaded or must be streamed). Also, we consider compatibility with popular video streaming services (i.e., YouTube, ScreenCast, etc.).

\section{File Size}

To compare file sizes we took a 5:52 sample lecture video and encoded it using the various file formats using Camtasia. The video length was kept at the longest recommended time (about 6 minutes) for online educational videos (Guo, et. al. 2014). The file size (640X480), frame rate (30 frames per second), and other options were kept constant. We used no compression for those files sizes that allow for compression. The results appear in Table 1. As expected, the avi file format produced the largest file size by far. The QuickTime format produced the smallest file size; however, as mentioned above it has been replaced by MPEG-4. While the Flash file format was about four times larger than .wmv and .mp4, it should be noted that Flash is optimized for streaming - so overall file size is not as important. 
Table 1. File Size

\begin{tabular}{l|c}
\hline File Format & Size \\
\hline AVI & $14.6 \mathrm{~GB}$ \\
\hline WMV & $28.4 \mathrm{MB}$ \\
\hline QuickTime & $15.2 \mathrm{MB}$ \\
\hline MPEG-4 & $35 \mathrm{MB}$ \\
\hline Flash & $130 \mathrm{MB}$ \\
\hline
\end{tabular}

\section{Portability}

Portability has become a major ease of use factor regarding distributing video in an educational setting. Students can select from a large assortment of computing devices on which to view videos. These now include not only computers but mobile phones and tablets. Using a video format that is not easily available across all devices will leave some students unable to view the video.

In Table 2 we compare the video formats against the major currently available computing platforms. We developed the list by considering the most widely used operating systems and mobile device platforms (IDC 2015). We removed platforms that were not likely widely used by most students (e.g., BlackBerry).

The table shows whether the format is supported natively (meaning no additional software or plugin is required), required a software or plugin install, or not supported at all.

An obvious problem for faculty is the complete inability of iOS-based devices to play Flash content, a deliberate strategy on the part of Apple, and must be taken into consideration given the popularity of iOS devices among students. Also, in all cases, a Flash browser plugin or software must be installed.

MPEG-4 has the most native support across platforms. However, it is missing from Windows Media Player prior to version 12. Windows Media Player version 12 comes installed with Windows 10, but it could be problematic for students who still use older versions of Windows.

Table 2. Portability

\begin{tabular}{|c|c|c|c|c|}
\hline File Format & Windows & Mac OSX & $\begin{array}{c}\text { iOS (iPod/iPhone/ } \\
\text { iPad) }\end{array}$ & Android \\
\hline AVI & $\begin{array}{l}\text { Native (via Windows } \\
\text { Media Player) }\end{array}$ & $\begin{array}{l}\text { Software Install } \\
\text { Required }\end{array}$ & $\begin{array}{l}\text { Software (app) Install } \\
\text { Required }\end{array}$ & $\begin{array}{l}\text { Software (app) Install } \\
\text { Required }\end{array}$ \\
\hline WMV & $\begin{array}{l}\text { Native (via Windows } \\
\text { Media Player) }\end{array}$ & $\begin{array}{l}\text { Software Install } \\
\text { Required }\end{array}$ & $\begin{array}{l}\text { Software (app) Install } \\
\text { Required }\end{array}$ & $\begin{array}{l}\text { Software (app) Install } \\
\text { Required }\end{array}$ \\
\hline QuickTime & $\begin{array}{l}\text { Native (via Windows } \\
\text { Media Player) }\end{array}$ & Native (via iTunes) & Native & $\begin{array}{l}\text { Software (app) Install } \\
\text { Required }\end{array}$ \\
\hline MPEG-4 & $\begin{array}{l}\text { Requires Windows } \\
\text { Media Player } 12 \text { or } \\
\text { Plugin for Earlier } \\
\text { Versions }\end{array}$ & Native (via iTunes) & Native & Native \\
\hline Flash & $\begin{array}{l}\text { Browser Plugin } \\
\text { Required }\end{array}$ & $\begin{array}{l}\text { Browser Plugin } \\
\text { Required }\end{array}$ & Not supported & $\begin{array}{l}\text { Software (app) Install } \\
\text { or Browser Plugin } \\
\text { Required }\end{array}$ \\
\hline
\end{tabular}

[http://support.microsoft.com/kb/316992]

\section{Distribution}

Once a video has been created, it still needs to be effectively distributed to students. Streaming video from the Web is a good solution in that it enables students to begin viewing immediately - rather than having to wait for the entire file to download. However, some students might prefer to download video to view it while they are offline. 
Therefore, formats that offer both options allow for the greatest flexibility.

Table 3 compares each video format based on its distribution methods. In addition to the ability to download the file, we also chose the ability to upload the file to YouTube and ScreenCast. YouTube is, by far, the most widely used video sharing service. It allows users to upload videos, of no longer than 15 minutes in length. ScreenCast was also selected as it is integrated with the popular video capture software Camtasia (TechSmith owns both).

It is clear that only Flash cannot be easily downloaded (there are browser plugins and other software that enable download of Flash video). Since Flash is optimized for streaming, this is to be expected. Both WMV and MPEG-4 are available for download and can be streamed by both YouTube and ScreenCast.

Table 3. Video Distribution

\begin{tabular}{l|c|c|c}
\hline \multicolumn{1}{c|}{ File Format } & Download & YouTube & ScreenCast \\
\hline AVI & Yes & Yes & No \\
\hline WMV & Yes & Yes & Yes \\
\hline QuickTime & Yes & No & Yes \\
\hline MPEG-4 & Yes & Yes & Yes (preferred) \\
\hline Flash & No & Yes & Yes \\
\hline
\end{tabular}

\section{CONCLUSIONS AND BEST PRACTICES}

As more and more universities are offering online and hybrid courses and programs, serious consideration needs to be placed on providing high quality and easy to use course content. As most asynchronous online courses rely on Internet videos to deliver course content, the choice of video format may become crucial to the success of the online course.

This research presented an overview of the various video formats and a head-to-head comparison with regards to file size, portability, and distribution. Although we have not considered much of the technical details involved with each format, we recognize that this is a complex decision with many pros and cons for each format.

It is clear from the comparisons made above that certain file formats should be avoided for educational use. The AVI format produces video that is too large and cannot be played natively on most devices. However, since the AVI format is uncompressed there are some instances where its use may be desirable - in a film class where students need to edit video uploaded by the instructor for example. Flash is a very popular method for delivering online video. However, the difficulty involved in downloading Flash files and the inability of iOS devices to play Flash make this format unsuitable in an educational setting. Also, the adoption of HTML5 should make Flash increasingly obsolete over the next few years. QuickTime is an older format and has been largely replaced by MPEG-4 and, therefore, should not be used going forward.

The two main file formats that are appropriate for online teaching seem to be WMV and MPEG-4. Both generated files of about the same length. WMV has the benefit of playing natively on Windows-based computers, which are still the most popular. MPEG-4 can play natively on newer PCs, Mac OSX, and mobile devices. Both formats allow for downloading and playing on YouTube and Screencast. Therefore, the decision may come down to faculty, student, or institutional preference. For example, if the institution decides to provide students with iPads (as some universities are now doing) then MPEG-4 should be used for video content.

To optimize the development of online and hybrid courses and programs, universities should consider adopting an institutional standard format and approach. With an institutional standard, universities can provide support staff to train faculty and students in the development, distribution, and use of the videos. Once faculty become accustomed to the standard, they will be more receptive to developing online and hybrid courses and producing video content to support learning. Once students become accustomed to the standard, they will be more receptive to enrolling in online and hybrid courses. 
Another important consideration is the integration of the video content to the universities learning management systems. Ideally, students should be able to access all course related content via their learning management system including video content.

In today's academic culture, online enrollments have continued to grow at rates far more than the total higher education student population. As such, offering online and hybrid programs and courses have become a necessity for universities in a highly competitive higher education marketplace. Selecting the "best" tools, including video formats, for delivering those courses will be integral to their success.

\section{AUTHOR BIOGRAPHIES}

Dr. Ross A. Malaga a Professor in the Department of Information Management and Business Analytics in the Feliciano School of Business at Montclair State University. His research focuses on equity crowdfunding, online teaching and learning, and search engine optimization. He has published articles in Communications of the ACM, Decision Support Systems, Journal of Organizational Computing and Electronic Commerce, Electronic Commerce Research, and the Journal of Electronic Commerce in Organizations. Dr. Malaga earned his Ph.D. in Information Systems from George Mason University. E-mail: malagar@montclair.edu

Nicole B. Koppel is a Professor in the Department of Information Management and Business Analytics. Dr. Koppel's research focus is in the broad area of Assessment in Technology, Online Education, and Quantitative Studies. Her research can be found in peer-reviewed journals including: Journal of Informatics and Education Research, Decision Sciences Journal of Innovative Education, and T.H.E. Journal. Her teaching experience includes courses in Operations, Statistics and Information Systems. Dr. Koppel earned her Ph.D. in Management Science / Information Systems from Rutgers University; she also holds a B.S. and M.S. in Operations Research Engineering from Cornell and Columbia Universities, respectively. E-mail: koppeln@mail.montclair.edu

\section{REFERENCES}

Allen, I. E. and Seaman, J, (2014). "2015 Online Report Card - Tracking Online Education in the United States", The Sloan Consortium, January 2016. Available at http://onlinelearningconsortium.org/read/online-report-card-tracking-onlineeducation-united-states-2015/

Armstrong, April W., Nayla Z. Idriss, and Randie H. Kim (2011) "Effects of video-based, online education on behavioral and knowledge outcomes in sunscreen use: a randomized controlled trial." Patient education and counseling 83.2: 273-277.

Chester, A., Buntine, A., Hammond, K., \& Atkinson, L. (2011). Podcasting in education: Student attitudes, behaviour and selfefficacy. Educational Technology \& Society, 14(2), 236-247.

Davis, F. D. (1989), "Perceived usefulness, perceived ease of use, and user acceptance of information technology", MIS Quarterly 13(3): 319-340

Guo, Philip J., Juho Kim, and Rob Rubin. (2014) "How video production affects student engagement: An empirical study of mooc videos." Proceedings of the first ACM conference on Learning@ scale conference. ACM.

Hill, J. L., \& Nelson, A. (2011). New technology, new pedagogy? Employing video podcasts in learning and teaching about exotic ecosystems. Environmental Education Research, 17(3), 393-408. doi:10(1080/13504622), 2010, 545873.

Kay, Robin H. (2012) "Exploring the use of video podcasts in education: A comprehensive review of the literature." Computers in Human Behavior 28.3: 820-831.

"Smartphone OS Market Share", (2015) Q2. Retrieved on Aug. 5, 2016 from http://www.idc.com/prodserv/smartphone-osmarket-share.jsp

Vernocchi, Marco, Carlier, Bouchra, and Mishra, Bikash (2013) "Multi-tasking and Taking Control, Winning the Trust of the Sophisticated Consumer: Video-Over-Internet Consumer Survey”, Accenture, 2013. 